\title{
Impact of severity, duration, and etiology of hyperthyroidism on bone turnover markers and bone mineral density in men
}

\author{
El Hadidy M El Hadidy ${ }^{1 \dagger}$, Mohamed Ghonaim ${ }^{1 \dagger}$, Soma Sh Abd El Gawad ${ }^{2 *}$ and Mohamed Abou El Atta ${ }^{3+}$
}

\begin{abstract}
Background: Hyperthyroidism is accompanied by osteoporosis with higher incidence of fracture rates. The present work aimed to study bone status in hyperthyroidism and to elucidate the impact of severity, duration, and etiology of hyperthyroidism on biochemical markers of bone turnover and bone mineral density (BMD).
\end{abstract}

Methods: Fifty-two male patients with hyperthyroidism, 31 with Graves' disease (GD) and 21 with toxic multinodular goiter (TNG), with an age ranging from 23 to 65 years were included, together with 25 healthy euthyroid men with matched age as a control group. In addition to full clinical examination, patients and controls were subjected to measurement of BMD using dual-energy $X$-ray absorptiometery scanning of the lower half of the left radius. Also, some biochemical markers of bone turnover were done for all patients and controls.

Results: Biochemical markers of bone turnover: included serum bone specific alkaline phosphatase, osteocalcin, carboxy terminal telopeptide of type I collagen also, urinary deoxypyridinoline cross-links (DXP), urinary DXP/urinary creatinine ratio and urinary calcium/urinary creatinine ratio were significantly higher in patients with GD and TNG compared to controls $(P<0.01)$. However, there was non-significant difference in these parameters between $G D$ and TNG patients ( $P>0.05$ ). BMD was significantly lower in GD and TNG compared to controls, but the Z-score of BMD at the lower half of the left radius in patients with GD (-1.7 $\pm 0.5 \mathrm{SD})$ was not significantly different from those with TNG $(-1.6 \pm 0.6 \mathrm{SD})(>0.05)$. There was significant positive correlation between free T3 and free T4 with biochemical markers of bone turnover, but negative correlation between TSH and those biochemical markers of bone turnover. The duration of the thyrotoxic state positively correlated with the assessed bone turnover markers, but it is negatively correlated with the Z-score of BMD in the studied hyperthyroid patients $(r=-0.68, P<0.0001)$.

Conclusion: Men with hyperthyroidism have significant bone loss with higher biochemical markers of bone turnover. The severity and the duration of the thyrotoxic state are directly related to the derangement of biochemical markers of bone turnover and bone loss.

Keywords: Bone mineral density, Bone formation markers, Bon resorption markers, Hyperthyroidism, Osteoporosis

\section{Background}

Thyroid hormones are necessary for normal skeletal growth, maturation, basic metabolism, and bone turnover [1]. Hyperthyroidism is accompanied by osteoporosis or osteopenia with increased rates of bone formation

\footnotetext{
* Correspondence: somaabdelgawad@yahoo.com

† Contributed equally

${ }^{2}$ Clinical Pathology Department, Faculty of Medicine, Mansoura University,

Egypt

Full list of author information is available at the end of the article
}

and bone resorption with predominance of resorption $[2,3]$. And higher incidence of fracture rates [4].

Bone densitometric studies revealed that bone mineral density (BMD) is decreased in all skeletal sites, including spine, femur, radius, and total body in patients with hyperthyroidism [5]. However, the deleterious effect of excess thyroid hormone on bone is reported to be more accentuated in areas consisting mainly of cortical bone like femoral neck and forearm $[3,6]$. On the other hand, Jodar et al (1997) reported that, there is also, a generalized reduction of BMD in the axial skeleton [7].

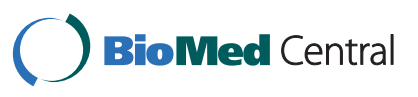


However, assessment of bone mass in patients with hyperthyroidism is recommended in cortical bones than trabecular bones [8].

Biochemical markers that reflect remodeling or turnover of bone can be measured in urine or blood including resorption markers and formation markers [9]. Resorption markers include tartrate resistant acid phosphatase, and products of bone breakdown as calcium and bone matrix degradation products like hydroxyproline, pyridinium cross-links, and telopeptides [10]. Bone formation markers include alkaline phosphatase enzyme, and three products of bone matrix synthesis which are osteocalcin, amino-and carboxy-terminal procollagen 1 extension peptide $[11,12]$.

It is reported that bone resorption markers, as urinary pyridinoline and deoxypyridinoline are increased 7-8 times in hyperthyroidism more than age and sex matched controls [13]. On the other hand, serum osteocalcin and bone-specific alkaline phosphatase, reflecting bone formation, were increased to a less degree compared to the increase of urinary pyridinoline cross-links, suggesting the imbalance between bone formation and resorption with subsequent bone loss in hyperthyroidism $[2,14]$.

There is paucity of data about the relation between the degree of hyperthyroidism, its duration, or its etiology and the resulting bone changes. The aim of the present study was to evaluate the bone mineral density and selected bone turnover markers in patients with hyperthyroidism, also to elucidate the impact of severity, duration and etiology of hyperthyroidism on these biochemical markers and bone mineral density.

\section{Methods}

\section{Subjects}

This work included 52 male patients with hyperthyroidism, receiving antithyroid agents during a period of 1-7 years, having normal FT3, FT4 and TSH levels for at least 6 months prior to the study, among those who were attending the Endocrine Out Patients Clinic of Mansoura University Hospitals, 31 with toxic Graves' disease (GD) and 21 with toxic multinodular goiter (TNG). Their age ranged from 23 to 65 years. A control group of 25 healthy men with matched age were included, their age ranged from 25 to 63 years.

Exclusion criteria included: women to nullify the effect of gender on the bone status, patients with co-morbidity (hypo-and hyper parathyroidism, vitamin D deficiency, Cushing's disease, diabetic nephropathy, inflammatory bowel disease, malabsorptive disease or renal diseases) or on medication (steroid, bisphosphonates, calcium or vitamin D) influencing bone turnover. Also patients with history of previous surgery or radiotherapy to the thyroid gland were excluded.
All participants provided written informed consent after receiving oral and written information concerning the study. The study protocol was approved by local ethical committee of the hospital. All patients and controls were subjected to: Full clinical examination, thyroid function tests (serum free $\mathrm{T} 3$, free $\mathrm{T} 4$ and $\mathrm{TSH}$ ), radioactive isotope scanning and uptake of the thyroid gland with Technicium 99.

\section{Methods}

In all patients and controls bone mineral density (BMD) was determined by dual X-ray absorptiometry (DEXA, Hologic QDR 1000 Analyzer) of the lower half of the left radius as the non-dominant hand; data were expressed as a real density in $\mathrm{g} / \mathrm{m}^{2}$ and as Z-score which is calculated by substracting the mean BMD of an age, ethnicity and sex matched reference population from the patients BMD and dividing the difference by the SD of the reference population.

Special biochemical assays included serum total calcium, phosphorus, total alkaline phosphatase, bone-specific alkaline phosphatase (B-ALP), osteocalcin (OC) and carboxy terminal telopeptide of type l collagen $(\beta-\mathrm{CTx})$. Also, urinary calcium, urinary deoxypyridinoline (DXP) and urinary creatinine, were done for both patients and control.

Blood samples were drawn after an overnight fasting from patients and controls and sera were separated and divided into 2 plain tubes. Serum obtained from one of them was used for estimation of total calcium, phosphorus and total alkaline phosphatase using Roche Cobas Integra 400 plus analyzer, Germany[15,16]. The other tube was centrifuged at $1500 \times \mathrm{g}$ for $15 \mathrm{~min}$ then serum was stored frozen at $-70^{\circ} \mathrm{C}$ until analysis of the following:

- Serum bone specific alkaline phosphatase (B-ALP) concentration was measured with a non-competitive enzyme immunoassay technique (Quidel Corporation, San Diego, CA, USA) [17].

- Serum free T3, free T4 and TSH levels were assayed by electrochemiluminescence immunoassay using Roche Elecsys 2010 immunoassay analyzer, Germany [18].

- Serum osteocalcin was analyzed using an immunoenzymatic assay for quantitative measurement of intact human osteocalcin (h-ost) using a kit supplied by Biosource Europe S.A, Belgium, according to the method of Power and Fortell (1991) [19].

- Serum carboxy terminal telopeptide of type 1 collagen ( $\beta$-CTx) was assayed by electrochemiluminescence immunoassay using Roche Elecsys 2010 immunoassay analyzer, Germany [20].

At the same time, urine were collected for twenty four hours, urine volume measured then $10 \mathrm{ml}$ was stored in Falcon tubes at $-70^{\circ} \mathrm{C}$ until assay of urine calcium, creatinine and deoxypyridinoline. 
- Urine deoxypyridinoline was analyzed by Immulite Pyrilinks-D chemiluminscent enzyme-labeled immunoassay using Immulite-1000 DPC, Los Angeles, according to the method of Reid et al (2004) [21]. Urinary deoxypyridinoline (DXP) was corrected for urinary creatinine and a ratio of DXP in $\mathrm{nmol} / \mathrm{l} /$ urinary creatinine in $\mathrm{mg} / \mathrm{dl}$ was calculated.

\section{Statistical Methods}

Data were statistically analyzed using SPSS computerized package by Fisher's exact test to compare differences in rates and Student t-test for differences in parametric data. Significance of correlation and the relative contribution of each variable were assessed by Spearman Rank correlation test. P value $<0.05$ was considered significant.

\section{Results}

Table 1: Showed the clinical data (as age, body weight, hight, body mass index BMI and duration of thyrotoxic state) and the results for thyroid function test for all hyperthyroid patients (GD\&TNG) and controls.

Table 2: In patients with GD and TNG, there were significantly higher serum levels of B-ALP $(\mathrm{P}<0.01)$, OC $(\mathrm{P}<0.0001), \beta-\mathrm{CTx}(\mathrm{P}<0.01)$ compared to controls. Also urinary calcium/urinary creatinine ratio, urinary DXP and urinary DXP/urinary creatinine ratio were significantly higher in GD and TNG patients compared to controls $(\mathrm{P}<0.01)$. At the same time, $\mathrm{BMD}$ was significantly lower in patients with GD and TNG compared to controls. However, there were non-significant difference in patients with Graves' disease compared to those with toxic nodular goiter, as regard bone formation markers (serum B-ALP and osteocalcin), bone resorption markers (serum $\beta-C T x$, urinary calcium/urinary creatinine, urinary DXP and urinary DXP/urinary creatinine ratio) and BMD ( $\mathrm{P}>0.05)$.

Correlation between free T3 and biochemical markers of bone turnover revealed a significant positive correlation with all studied parameters. B-ALP $(r=0.37$, $\mathrm{P}<0.01)$, serum OC $(\mathrm{r}=0.62, \mathrm{P}<0.001)$, serum $\beta$-CTx $(\mathrm{r}=0.60, \mathrm{P}<0.001)$, urinary calcium/urinary creatinine ratio $(\mathrm{r}=0.46, \mathrm{P}<0.01)$ and urinary $\mathrm{DXP} /$ urinary creatinine ratio $(\mathrm{r}=0.52, \mathrm{P}<0.001)$. Also, correlation between free $\mathrm{T} 4$ and bone turnover markers revealed a significant positive correlation with B-ALP $(\mathrm{r}=0.43, \mathrm{P}<$ $0.01)$, serum $\mathrm{OC}(\mathrm{r}=0.65, \mathrm{P}<0.001)$, serum $\beta$-CTx $(\mathrm{r}$ $=0.65, \mathrm{P}<0.001)$, urinary calcium $/$ urinary creatinine ratio $(\mathrm{r}=0.61, \mathrm{P}<0.001)$ and urinary $\mathrm{DXP} /$ urinary creatinine ratio $(r=0.49, \mathrm{P}<0.01)$. While, significant negative correlation between TSH and biochemical markers of bone turnover was present, B-ALP $(r=-0.39, \mathrm{P}$ $<0.01)$, serum OC $(\mathrm{r}=-0.42, \mathrm{P}<0.01)$, serum $\beta-\mathrm{CTx}(\mathrm{r}$ $=-0.36, \mathrm{P}<0.01)$, urinary calcium/urinary creatinine $(\mathrm{r}$ $=-0.26, \mathrm{P}<0.05)$ and urinary $\mathrm{DXP} /$ urinary creatinine ratio $(\mathrm{r}=-0.32, \mathrm{P}<0.05)$ (Figure $1 \& 2)$.

Z-score of Bone mineral density measured at the lower half of the left radius in patients with Graves' disease $(-1.7 \pm 0.5)$ was not significantly different from those with toxic multinodular goiter $(-1.6 \pm 0.6)$ (table 3$)$.

Correlation between the Z-score of BMD in hyperthyroid patients and free $\mathrm{T} 3$, free $\mathrm{T} 4$ as well as biochemical markers of bone turnover revealed a nonsignificant relation with any of them ( $\mathrm{r}$ value for B-ALP -0.18 , serum OC $r=-0.14$, Serum $\beta$-CTx $r=-0.15$, urinary calcium $\mathrm{r}=-0.09$ and urinary DXP/urinary creatinine ratio $\mathrm{r}=-0.12$ ) (table 4 ). While, correlation between duration of the thyrotoxic state and assessed bone turnover markers revealed a significant positive correlation with all of them. However, the BMD measured as real density $\left(\mathrm{g} / \mathrm{m}^{2}\right)$ or Z-score in the studied hyperthyroid patients was negatively correlated with the duration of thyrotoxic state $(\mathrm{r}=-0.68, \mathrm{P}<0.05)$ (table 5) (Figure 3).

\section{Discussion}

Remodeling is essential for bone health. Remodeling is coupled with simultaneous formation and resorption of

Table 1 Clinical characteristics and thyroid functions tests of patients with hyperthyroidism (GD and TNG) and controls.

\begin{tabular}{|c|c|c|c|c|c|}
\hline Parameters & $G D(n=31)$ & TNG $(n=21)$ & Controls $(n=25)$ & P1 & $P 2$ \\
\hline Age (years) & $43 \pm 10$ & $44 \pm 8$ & $42 \pm 11$ & $>0.05$ & $>0.05$ \\
\hline Body weight (kg) & $69.5 \pm 8.0$ & $68.0 \pm 12.0$ & $86.0 \pm 10.0$ & $<0.05$ & $<0.05$ \\
\hline Hight $(\mathrm{cm})$ & $170 \pm 10$ & $173 \pm 10$ & $173 \pm 13$ & $>0.05$ & $>0.05$ \\
\hline$B M I\left(\mathrm{~kg} / \mathrm{m}^{2}\right)$ & $27.5 \pm 3.1$ & $27.8 \pm 2.8$ & $30.2 \pm 2.9$ & $>0.05$ & $>0.05$ \\
\hline Duration of disease (years) & $2.9 \pm 1.2$ & $3.0 \pm 1.5$ & - & - & - \\
\hline Serum TSH (uU/ml) & $0.89 \pm 0.47$ & $1.01 \pm 0.36$ & $3.31 \pm 0.76$ & $<0.01$ & $<0.01$ \\
\hline Serum Free T3 (pmol/l) & $6.14 \pm 2.32$ & $5.62 \pm 1.42$ & $4.57 \pm 1.43$ & $<0.01$ & $<0.05$ \\
\hline Serum Free T4 (pmol/l) & $20.8 \pm 6.2$ & $19.8 \pm 5.7$ & $17.9 \pm 4.26$ & $<0.05$ & $<0.05$ \\
\hline
\end{tabular}

P1: Graves' diseases (GD) vs control

P2: Toxic multinodular goiter (TNG) vs control

Significant $\mathrm{P}<0.05$ 
Table 2 Markers of bone turnover and BMD in patients with Graves' disease and toxic multinodular goiter versus control.

\begin{tabular}{|c|c|c|c|c|c|c|}
\hline \multirow[t]{2}{*}{ Parameters } & \multirow{2}{*}{$\begin{array}{c}G D \\
(n=31)\end{array}$} & \multirow{2}{*}{$\begin{array}{c}\text { TNG } \\
(n=21)\end{array}$} & \multirow{2}{*}{$\begin{array}{l}\text { Controls } \\
(n=25)\end{array}$} & \multicolumn{3}{|c|}{ Significant } \\
\hline & & & & $P 1$ & $P 2$ & P3 \\
\hline Serum B-ALP (KAU/I) & $4.9 \pm 3.6$ & $4.3 \pm 2.6$ & $2.2 \pm 0.8$ & $<0.01$ & $<0.01$ & $>0.05$ \\
\hline Serum calcium (mg/dl) & $9.5 \pm 1.0$ & $9.8 \pm 1.0$ & $9.8 \pm 0.5$ & $>0.05$ & $>0.05$ & $>0.05$ \\
\hline Serum phosphorus (mg/dl) & $3.9 \pm 0.6$ & $4.0 \pm 0.6$ & $4.0 \pm 0.7$ & $>0.05$ & $>0.05$ & $>0.05$ \\
\hline Serum osteocalcin (ng/ml) & $12.9 \pm 4.0$ & $11.9 \pm 4.1$ & $6.6 \pm 1.6$ & $<0.0001$ & $<0.0001$ & $>0.05$ \\
\hline Serum $\beta$-CTx (ug/l) & $4.5 \pm 0.8$ & $4.1 \pm 0.6$ & $3.3 \pm 0.6$ & $<0.01$ & $<0.01$ & $>0.05$ \\
\hline Ur. calcium/urinary creatinine & $0.54 \pm 0.07$ & $0.49 \pm 0.05$ & $0.36 \pm 0.05$ & $<0.001$ & $<0.01$ & $>0.05$ \\
\hline UDXP (nmol/l) & $68 \pm 24$ & $73 \pm 22$ & $49.8 \pm 26$ & $<0.01$ & $<0.01$ & $>0.05$ \\
\hline UDXP/urinary creatinine & $12.6 \pm 5.5$ & $13.5 \pm 5.0$ & $6.3 \pm 1.8$ & $<0.001$ & $<0.001$ & $>0.05$ \\
\hline BMD at lower radius $\left(\mathrm{g} / \mathrm{cm}^{2}\right)$ & $0.780 \pm 0.215$ & $0.799 \pm 0.232$ & $0.952 \pm 0.170$ & $<0.01$ & $<0.01$ & $>0.05$ \\
\hline
\end{tabular}

Data: Mean \pm SD

Significant $P$ at $<0.05$

bone, but after middle age bone loss occurs because resorption exceeds formation. This imbalance is aggravated by many disease states [22]. Hyperthyroidism is one of the conditions associated with bone loss and increased fracture risk $[4,23,24]$. Biochemical markers that reflect remodeling can be assessed in blood or urine $[9,13]$. In the present work, we aimed to study some markers of bone turnover and bone mineral density and their relation to hyperthyroidism with different etiology.

The significantly higher bone formation markers (serum bone specific alkaline phosphatase and serum osteocalcin) and bone resorption markers (Serum $\beta$ CTx, urinary calcium and urinary deoxypyridinoline) in both patients with toxic Graves' disease and toxic multinodular goiter, found in the present work, confirms the high turnover state in the skeleton of patients with hyperthyroidism. There was a significant correlation between both free T3 and free T4 to B-ALP, serum OC as bone formations markers, and Serum $\beta-\mathrm{CTx}$, urinary calcium/urinary creatinine ratio, urinary DXP and urinary DXP/urinary creatinine ratio as bone resorption markers. The high bone turnover markers in thyrotoxic patients with significant decrease in bone mineral density proved by the Z-score of the studied patients confirms the thyrotoxic osteopathy reported by many authors [2,4,9,14,23-26].

Thyroid hormones affect bone cells both in vitro and in vivo by stimulating osteoblast and osteoclast cells with more bone resorption and increased skeletal remodeling [27]. The exact mechanism of the deleterious effect of thyroid hormone on bone is poorly understood $[23,24]$. However, some authors reported that, bone loss in thyrotoxicosis may be as a direct stimulating effect of excess thyroid hormone acting locally on bone [4]. Also, TSH deficiency could be partly responsible for the skeletal loss seen in thyrotoxicosis [23], because it has been proposed that TSH may be a direct negative regulator of bone turnover acting via the TSH receptor on both osteoblasts and osteoclasts $[24,28]$. As TSH inhibits
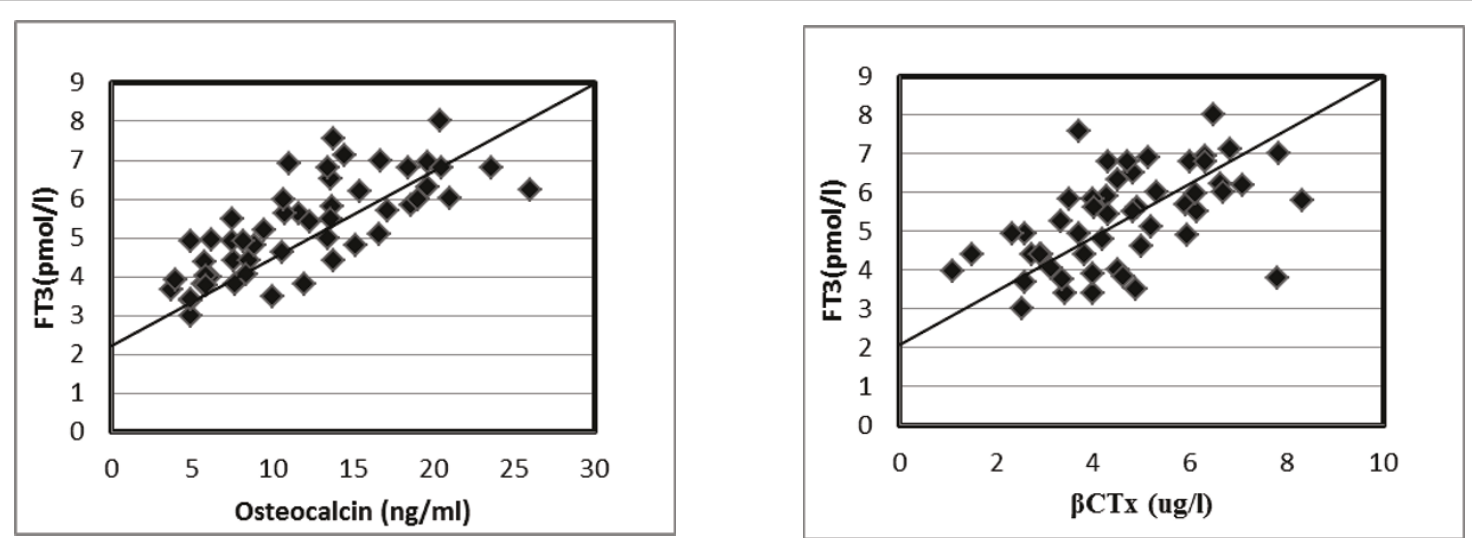

Figure 1 Positive correlation of Serum FT3 with osteocalcin and $\beta$-CTx levels for all hyperthyroid patients. 

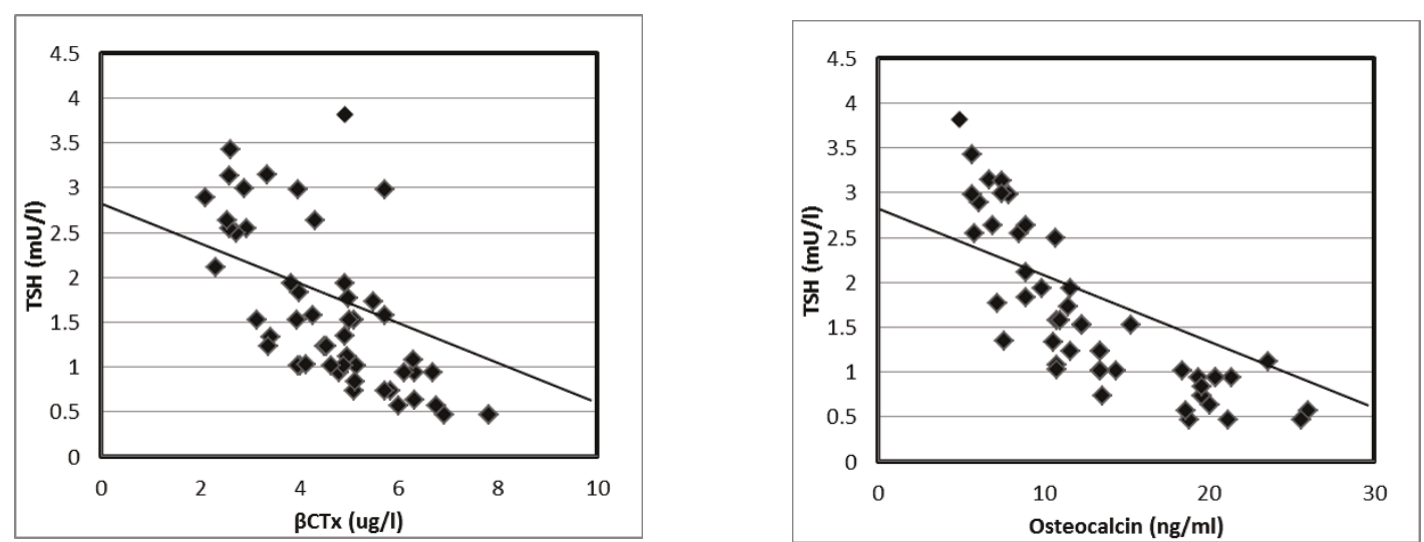

Figure 2 Negative Correlation of serum TSH with osteocalcin and $\beta$-CTx levels for all hyperthyroid patients.

Table 3 Z-score of bone mineral density in Graves' disease patients, toxic multinodular goiter patients and controls.

\begin{tabular}{|c|c|c|c|c|c|c|}
\hline & \multirow{2}{*}{$\begin{array}{l}\text { Graves' Disease } \\
\quad(n=31)\end{array}$} & \multirow{2}{*}{$\begin{array}{l}\text { Toxic Nodular } \\
\text { goiter }(n=21)\end{array}$} & \multirow{2}{*}{$\begin{array}{l}\text { Controls } \\
(n=25)\end{array}$} & \multicolumn{3}{|c|}{ Significance } \\
\hline & & & & $P 1$ & $P 2$ & $P 3$ \\
\hline Mean $\pm S D$ & $-1.7 \pm 0.5$ & $-1.6 \pm 0.6$ & $-0.20 \pm 0.26$ & $<0.000111$ & $<0.0001$ & $>0.05$ \\
\hline
\end{tabular}

P1: Graves' disease vs controls

P2: Toxic multinodular goiter vs controls.

P3: GD vs TNG

Table 4 Correlation between Z-score of bone mineral density in hyperthyroid patients with thyroid hormones as well as markers of bone turnover.

\begin{tabular}{ccccccc}
\hline Free T3 & Free T4 & $\begin{array}{c}\text { Serum } \\
\boldsymbol{B} \text {-ALP }\end{array}$ & $\begin{array}{c}\text { Serum } \\
\text { OC }\end{array}$ & $\begin{array}{c}\text { Serum } \\
\boldsymbol{\beta} \text {-CTx }\end{array}$ & $\begin{array}{c}\text { Urinary calcium/ } \\
\text { urinary creatinine }\end{array}$ & $\begin{array}{c}\text { Urinary DXP/ } \\
\text { urinary creatinine }\end{array}$ \\
\hline$r=-0.12$ & $r=-0.09$ & $r=-0.18$ & $r=-0.14$ & $r=-0.15$ & $r=-0.09$ & $r=-0.12$ \\
\hline$P>0.05$ & $P>0.05$ & $P>0.05$ & $P>0.05$ & $P>0.05$ & $P>0.05$ & $P>0.05$ \\
\hline
\end{tabular}

Table 5 Correlation between duration of thyroid disease with markers of bone turnover and Z-score of BMD at left radius.

\begin{tabular}{ccccccc}
\hline & $\begin{array}{c}\text { Serum } \\
\boldsymbol{B} \text {-ALP }\end{array}$ & $\begin{array}{c}\text { Serum } \\
\text { Osteocalcin }\end{array}$ & $\begin{array}{c}\text { Serum } \\
\boldsymbol{\beta} \text {-CTx }\end{array}$ & $\begin{array}{c}\text { Urinary Calcium/ } \\
\text { urinary creatnine }\end{array}$ & $\begin{array}{c}\text { UDXP/ } \\
\text { urinary creatinine }\end{array}$ & $\begin{array}{c}\text { Z-score } \\
\text { BMD }\end{array}$ \\
\hline $\boldsymbol{r}$ value & 0.33 & 0.28 & 0.29 & 0.34 & 0.25 & -0.68 \\
\hline significance & $<0.01$ & $<0.05$ & $<0.05$ & $<0.01$ & $<0.05$ & $<0.001$ \\
\hline
\end{tabular}

osteoclast formation and survival and also inhibits osteoblasts differentiation [29]. In addition, increased serum interleukin-6 concentration in hyperthyroid patients favors osteoclasts production may be effectors of the action of parathyroid hormones on bone $[2,4]$.

Several factors may be incriminated in thyrotoxic bone loss [30]. Severity and duration of the hyperthyroid state are related to bone turnover and bone mass [11,31]. In the present study, duration of the disease was proved to be significantly related to bone mineral density as measured by real density and Z-score, also it was significantly related to the bone turnover markers, both of bone formation as serum B-ALP and serum OC, or bone resorption markers as Serum $\beta$-CTx, urinary calcium, urinary DXP and urinary DXP/urinary creatinine ratio. This comes in disagreement with Diamond et al (1994) who did not find a relation between the duration of the thyrotoxic state and the degree of bone loss in their study on pre- and postmenopausal women [32]. It is noteworthy that the present work studied men while, they studied pre-and postmenopausal women. Also, Nekrasova et al (2005) found that, the reduction in 


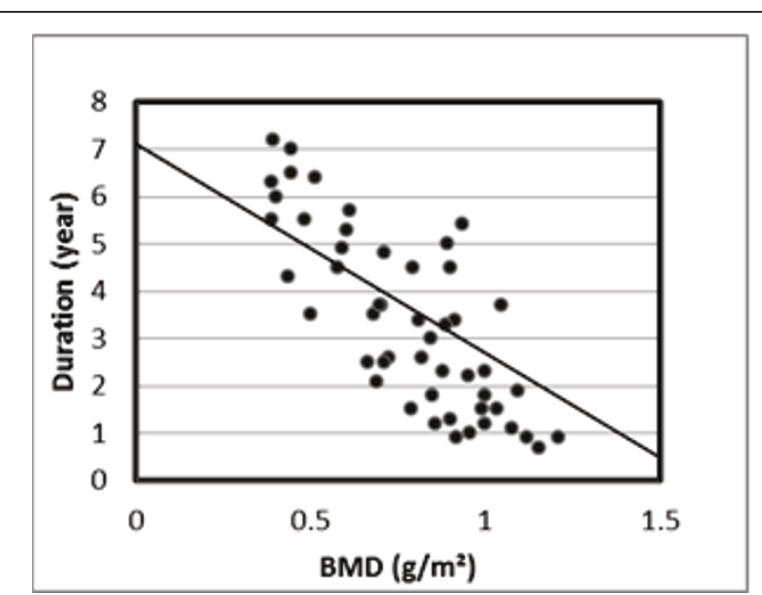

Figure 3 Negative correlation of disease duration with BMD for all hyperthyroid patients.

BMD most frequent and severe in patients with severe thyrotoxicosis but this loss of BMD does not depend on disease duration [31].

Bone densitometric studies proved that all sites of bone including axial and appendicular skeleton were affected in patients with hyperthyroidism [33], but Van de ven and Erdtsieck studies (2008) revealed that changes in cortical bone (appendicular skeleton like femur and radius) were more prominent than cancellous bone (axial skeleton as spine) [4]. In the present study, bone densitometry was done on the left radius and BMD Z-score for patients with toxic GD was not significantly different from that of patients with TNG. Furthermore, markers of bone turnover, whether of bone formation (serum B-ALP and OC) or bone resorption markers (Serum $\beta$-CTx, urinary DXP, urinary DXP/urinary creatinine ratio and urinary calcium/urinary creatinine ratio) were not significantly different in both categories of patients. This finding confirms the report of Jodar et al (1997) and Belaya et al (2007), they found no difference in bone mineral density in patients with Graves' disease compared to those with toxic multinodular goiter [7,34].

In the present work, although confirming decreased bone mineral density in the studied patients, there was a non-significant relation to either free $\mathrm{T} 3$ or free $\mathrm{T} 4$ or to any of the biochemical markers of bone turnover studied (B-ALP, serum OC, Serum $\beta$-CTx, urinary DXP crosslinks, urinary DXP/urinary creatinine ratio and urinary calcium/urinary creatinine ratio). Variability in the duration of the thyrotoxic state could be the explanation behind the discordance between bone mineral density and severity of thyrotoxic state or bone turnover state.

\section{Conclusion}

It is concluded that men with hyperthyroidism have significant bone loss with higher biochemical markers of bone turnover. The severity and duration of hyperthyroidism directly related to the derangement of biochemical markers of bone turnover and to the degree of bone loss. The etiology of the thyrotoxic state is not related to the degree of derangement in bone turnover markers or to the degree of bone loss.

\section{Acknowledgements}

We are grateful to the support of our colleague for their assistance. Also, we are grateful for our patients and control subjects for their agreement to chair in this study.

\section{Author details}

${ }^{1}$ Internal Medicine Department, Faculty of Medicine, Mansoura University, Egypt. ${ }^{2}$ Clinical Pathology Department, Faculty of Medicine, Mansoura University, Egypt. ${ }^{3}$ Diagnostic Radiology Department, Faculty of Medicine, Mansoura University, Egypt.

\section{Authors' contributions}

MG conceived of the study, participated in its design and coordination, sequence alignment and drafted the manuscript. SSA participated in the sequence alignment and drafted the manuscript and carried out the immunoassays and carried out the statistical analysis. EM participated in the design of the study and sequence alignment. MA participated in the design of the study and performed the bone mineral density. All authors read and approved the final manuscript.

Received: 24 March 2011 Accepted: 6 August 2011

Published: 6 August 2011

\section{References}

1. Allain TJ, McGregor AM: Thyroid hormones and bone. J Endocrinol 1993, 139:9-18.

2. Akalin A, Colak O, Alatas O, Efe B: Bone remodeling markers and serum cytokines in patients with hyperthyroidism. Clin Endocrinol 2002, 57(1):125-129.

3. Udayakumar N, Chandrasekaran M, Rasheed MH, Suresh RV, Sivaprakash S: Evaluation of bone mineral density in thyrotoxicosis. Singapore Med J 2006, 47(11):947-950.

4. Van de ven AC, Erdtsieck RJ: Changes of bone mineral density, quantitative ultrasound parameters and markers of bone turnover during treatment of hyperthyroidism. The Netherlands J Medicine 2008, 66(10):428-432.

5. Vestergaard P, Mosekilde L: Hyperthyroidism, bone mineral, and fracture risk-a meta-analysis. Thyroid 2003, 13(6):585-593.

6. Campos-Pastor MM, Munoz-Torres M, Escobar-Jimenez F, et al: Bone mass in females with different thyroid disorders: influence of menopausal status. Bone and Mineral 1993, 21:1-8.

7. Jodar E, Munoz-Torres M, Escobar-Jimenez F, et al: Bone loss in hyperthyroid patients and in former hyperthyroid patients controlled on medical therapy: influence of etiology and menopause. J Clin Endocrinol 1997, 47:279-285.

8. Greenspan SL, Greenspan FS: The effect of thyroid hormone on skeletal integrity. Ann Intern Med 1999, 130(9):750-758.

9. Barsal G, Taneli F, Atay A, Hekimsoy Z, Erciyas F: Serum osteocalcin levels in hyperthyroidism before and after antithyroid therapy. Tohoku J Exp Med 2004, 203(3):183-188.

10. Kraenzlin ME, Seibel M: Measurement of biochemical markers of bone resorption. In Dynamics in bone and cartilage metabolism. Edited by: Seibel M, Robins S, Bilezikian J. Academic Press; 2006:541-564.

11. Al-Shoumer KAS, Vasanthy BA, Al-Zaid MM: Effects of treatment of hyperthyroidism on glucose homeostasis, insulin secretion and markers of bone turnover. Endocr Pract 2006, 12(2):121-130.

12. Naylor KE, Eastell R: Measurement of biochemical markers of bone formation. In Dynamics of bone and cartilage metabolism. Edited by: Seibel M, Robins S, Bilezikian J. Academic Press; 2006:529-540.

13. Kraenzlin ME, Kraenzlin CA, Meier C, Giunta C, Steinmann B: Automated HPLC assay for urinary collagen cross-links: effect of age, menopause, and metabolic bone diseases. Clin Chem 2008, 54:1546-1553. 
14. Kisakol G, Kaya A, Gonen S, Tunc R: Bone and calcium metabolism in subclinical autoimmune hyperthyroidism and hypothyroidism. Endocr $\mathrm{J}$ 2003, 50(6):657-661.

15. Endres DB, Rude RK: Mineral and bone metabolism. In Tietz fundamentals of clinical chemistry.. 4 edition. Edited by: Burtis CA, Ashwood ER. Philadelphia: WB Saunders; 1996:685-703.

16. Tietz NW, Shuey DF: Reference intervals for alkaline phosphatase. Activity determined by the IFCC and AACC reference methods. Clin Chem 1986, 32:1593-1594

17. Garnero P, Delmas PD: Assessment of the serum levels of bone alkaline phosphatase with a new immunoradiometric assay in patients with metabolic bone disease. J Clin Endocrinol Metab 1993, 77:1046-1053.

18. Ladenson PW: Optimal laboratory testing for diagnosis and monitoring of thyroid nodules, goiter and thyroid cancer. Clin Chem 1996, 42:1183-1187.

19. Power MJ, Fottrell PF: Osteocalcin: diagnostic methods and clinical applications. Crit Rev Clin Lab Sci 1991, 28(4):287-335.

20. Saetung $S$, Chailurkit LO, Ongphiphadhanakul B: Acute changes in biochemical markers of bone resorption and formation after Thai traditional massage. J Med Assoc Thai 2010, 93(7):771-775.

21. Reid IR, Davidson JS, Wattie D, Wu F, Lucas J, Gamble GD, Rutland MD, Cundy T: Comparative responses of bone turnover markers to bisphosphonate therapy in paget's disease of bone. $J$ Intern Bone and Miner Soci 2004, 35(1):224-230.

22. Wexler JA, Sharretts J: Thyroid and bone. Endocrinol Metab Clin North Am 2007, 36(3):673-705.

23. Galliford TM, Murphy E, Williams AJ, Bassett JH, Williams GR: Effects of thyroid status on bone metabolism: a primary role for thyroid stimulating hormone or thyroid hormone? Minerva Endocrinol 2005, 30(4):237-246.

24. Gogakos Al, Bassett JHD, Williams GR: Thyroid and bone. Arch Biochem Biophys 2010, 503(1):129-136.

25. Rosario PW: Bone and heart abnormalities of subclinical hyperthyroidism in women below the age of 65 years. Arq Bras Endocrinol Metab 2008, 52(9):1448-1451.

26. Williams GR: Actions of thyroid hormones in bone. Endokrynol Pol 2009, 60(5):380-388.

27. Bassett JHD, Williams GR: The molecular actions of thyroid hormones in bone. Trends Endocrinol Metab 2003, 14(8):356-364.

28. Abe E, Marians RC, Yu W, et al: TSH is a negative regulator of skeletal remodeling. Cell 2003, 115(2):151-162

29. Heijckmann AC, Huijberts MSP, Geusens P, Vries J, Menheere P, Wolffenbuttel B: Hip bone mineral density, bone turnover and risk of fracture in patients on long-term suppressive L-thyroxine therapy for differentiated thyroid carcinoma. European J Endocrinol 2005, 153(1):23-29.

30. Lee MS, Kim SY, Lee MC, et al: Negative correlation between the changes in bone mineral density and serum osteocalcin in patients with hyperthyroidism. J Clin Endocrinol Metab 1990, 70:766-770.

31. Nekrasova MR, Suplotova LA, Davydova LI: Features of osteopenic syndrome in diffuse toxic goiter. Ter Arkh 2005, 77(10):29-33.

32. Diamond T, Vine J, Smart R, et al: Thyrotoxic bone disease in women. A potentially reversible disorder. Ann Inter Med 1994, 120(1):8-11.

33. Marcocci C, Golia F, Bruno-Bossio G, et al: Carefully monitored levothyroxin suppressive therapy is not associated with bone loss in premenopausal women. J Clin Endocrinol Metab 1994, 78:818-823.

34. Belaya ZE, Melnichenko GA, Rozhinskaya LY, Fadeev W, et al: Subclinical hyperthyroidism of variable etiology and its influence on bone in postmenopausal women. Hormones 2007, 6(1):62-70.

\section{Pre-publication history}

The pre-publication history for this paper can be accessed here: http://www.biomedcentral.com/1472-6823/11/15/prepub

\section{doi:10.1186/1472-6823-11-15}

Cite this article as: El Hadidy et al:: Impact of severity, duration, and etiology of hyperthyroidism on bone turnover markers and bone mineral density in men. BMC Endocrine Disorders 2011 11:15.

\section{Submit your next manuscript to BioMed Central and take full advantage of:}

- Convenient online submission

- Thorough peer review

- No space constraints or color figure charges

- Immediate publication on acceptance

- Inclusion in PubMed, CAS, Scopus and Google Scholar

- Research which is freely available for redistribution

Submit your manuscript at www.biomedcentral.com/submit 